\title{
Myofascial trigger-point compression therapy as an adjunct to exercise program is superior in alleviating chronic low back pain compared to exercise program alone- A retrospective non- randomized study.
}

\section{Rawan Masarwa}

Hillel Yaffe Medical Center

Ofir Uri ( $\nabla$ ofiruri@gmail.com )

Hillel Yaffe Medical Center https://orcid.org/0000-0002-7497-4364

\section{Givon Peled}

Hillel Yaffe Medical Center

Gil Laufer

Hillel Yaffe Medical Center

Gabriel Gutman

Hillel Yaffe Medical Center

Eyal Behrbalk

Hillel Yaffe Medical Center

\section{Research article}

Keywords: Trigger points compression therapy, chronic low back pain, low back pain treatment, myofascial pain syndrome, low back pain prevention

Posted Date: January 11th, 2021

DOI: https://doi.org/10.21203/rs.3.rs-32741/v2

License: (c) (i) This work is licensed under a Creative Commons Attribution 4.0 International License.

Read Full License 


\section{Abstract}

Introduction: Current guidelines for the treatment of low back pain (LBP) endorse physical exercise programs and a range of non-pharmacological complementary therapies. Myofascial trigger points (MTP) compression therapy is a well-established form of manual therapy, which aims to induce temporary ischemia and over-stimulation of mechanoreceptors over a desired area in order to restore tissue normal functional conditions required for healing response. The purpose of the current study was to evaluate the effect of MTP compression therapy as an adjunct to active exercise program in alleviating chronic non-specific low back pain.

Methods: One-hundred and three patients with chronic non-specific LBP were retrospectively reviewed, 45 of them were treated with MTP compression therapy as an adjunct to physical exercise program and 58 were treated with exercise program alone. Pain and functional scores were compared before initiating treatment and at 3-month follow-up.

Results: Pain reduction at 3-month follow-up was 5.6 points (0-10 numerical scale) in the combined treatment group compared to 3.6 points in the exercise program alone group $(p<0.01)$. Oswestry Disability Index improved by 36 and 22 points respectively $(p<0.01)$ and SF-12 life quality score improved by 41 and 29 points respectively $(p<0.01)$.

Conclusions: Myofascial trigger points compression therapy as an adjunct to active exercise program provides superior pain and disability relief compared to active exercise program alone for patients with chronic LBP.

\section{Background}

Chronic low back pain (LBP) is one of the most common complaints in orthopedic practice, affecting millions of people around the world as a leading cause of disability [1, 2]. Among the variety of biophysical causes of chronic LBP, a myofascial origin of pain commonly exists and characterized by the presence of myofascial trigger points (MTP), located in fascia, tendons, and/or muscle, leading to symptomatic pain response [3]. MTP are small, 2-5mm nodules located in taut "rope-like" bands of skeletal muscle detectable in palpatory examination, which may generate considerable pain and discomfort. The processes in which MTP develop is not fully understood, however it is generally believed to be related to muscle overload and overuse $[4,5]$.

Although active exercise programs remain a first-line treatment for non-specific chronic LBP, passive manual therapies including massage and soft tissue compression techniques, remain therapeutic options [6].

Manual therapy aimed at MTP deactivation, for alleviating musculoskeletal pain, was firstly described in the 1980's by Travell and Simons, who recognized the relationship between MTP and myofascial pain syndrome [3]. It is suggested that continuous compression at MTP over-stimulates local 
mechanoreceptors which leads to neurotransmitters depletion and results in pain attenuation. Also, rapid reperfusion with oxygenated blood, ones the obstruction of the local blood flow is released, is believed to restore the normal functional conditions of the muscle and contribute to its recovery [7-9].

Several studies evaluated the effect of MTP compression therapy on musculoskeletal pain syndromes and found it to be effective in relieving pain and disability [10-12]. The added value of MTP compression therapy as an adjunct to standard commonly used active exercise program for the treatment of LBP in adults has not been assessed previously, to the best of our knowledge.

The purpose of the current study was to evaluate whether MTP compression therapy as an adjunct to conservative physical exercise program, focuses on core muscles strengthening, would provide clinical benefit compared to exercise program alone in alleviating chronic non-specific low back pain and disability in adults. We hypothesized that combined treatment would offer better outcome compared to active exercise program alone.

\section{Patients And Methods}

\section{Study design and participants}

We conducted a retrospective chart review, analyzing data of patients treated in our spine outpatient clinic between January 2017 and December 2018, who presented the following criteria on their initial visit: (1) non-specific LBP lasting for more than 3-month duration; (2) normal neurological examination with no findings of motor or sensory deficit; (3) no radicular symptoms or physical findings; (4) no "red flag" signs that may suggest a serious spine pathology (e.g., history of trauma, malignancy, fever, weight loss, neurological deficit, bladder or bowel dysfunction) [6]; (5) anterior-posterior and lateral lumbar spine radiographs with no pathological findings; (6) no medication prescribed; (7) an age of 18 to 65 years.

Patients who demonstrated these criteria were excluded:(1) radicular signs or neurological deficit; (2) previous spine injury or surgery; (3) systemic conditions which may induce pain (e.g., fibromyalgia, rheumatoid arthritis, malignancy, infection); (4) psychiatric disorders; (5) osteoporosis; (6) serious systemic pathology or pregnancy; (7) body-mass index (BMI) greater than $30 \mathrm{~kg} / \mathrm{m}^{2}$ (since palpation of MTP may be less accurate in obese patients $[7,8])$.

Clinical data and imaging studies were available for a retrospective review at our hospital medical records. The study was approved by our Institutional Ethics Committee.

\section{Study groups}


All the patients were treated in our spine surgery clinic by one of two spine consultants (E.B and G.G). Medical history and physical examination data were documented in the patient's file in real time, regardless of the study. According to our routine, after a diagnosis of non-specific LBP without neurological involvement was made, all patients were referred to conservative physical therapy, focusing on stretching and active core muscles strengthening. All patients were treated at the physical therapy department of our hospital by one of several trained physiotherapists experienced in treating patients with musculoskeletal disorders. The physical therapy exercise program included instructional and training sessions of 45 minutes twice a week for 4-6 weeks, in which the patients were instructed how to perform core muscles stretching and strengthening exercises independently at home on a daily basis. Thereafter, all patients attended a weekly check-up exercise session for additional 4-6 weeks. A follow-up visit in our outpatient spine clinic was scheduled for 3-month time. No medication was prescribed for the study cohort.

Patients who were initially seen by E.B, in addition to the aforementioned treatment plan, were also referred to a manual MTP compression therapy program. The manual MTP compression therapy program was supervised by a single manual therapist expert in alternative medicine and experienced in treating patients with musculoskeletal disorders (G.P). During the MTP compression therapy sessions the patients were instructed to lie down in the supine or prone position. Several MTP were identified over the lumbar erector spinae muscles and over the common main muscles associated with LBP (e.g., gluteus maximus, piriformis, hamstrings, quadratus lumborum, iliopsoas, tensor fascia lata) according to previously described diagnostic criteria including: (1) presence of a palpable hypersensitive taut band in the low back and associated muscles; (2) induction of pain similar to the patient's usual symptoms by compression at the MTP; (3) induction of pain by stretching the muscle including the MTP [12,13]. Manual constant pressure was applied to each MTP for a period of 1-2 minutes at controlled intensity aiming to produce pain response ranging between comfortable pain (approximately 4/10 on a 0-10 numerical scale) to maximally tolerable pain (approximately $7 / 10$ on a 0-10 numerical scale) [10-12]. The sequence of MTP compression was repeated for several times during a treatment session of 45 minutes, which was carried out once a week for 6 consecutive weeks.

\section{Outcome measures}

Patients were asked to complete clinical questionnaires at each outpatient visit, regardless of the study. The questionnaires included patients' self-reported: (1) back pain during daily activity using a 0 to 10 numerical scale, where 0 indicates no pain and 10 indicates severe pain; (2) back related disability using the Oswestry Disability Index (ODI) on a 0 to $100 \%$ scale, where a higher score indicates more disability and poorer function [14]; and (3) SF-12 life quality questionnaire on a 0 to $100 \%$ satisfaction scale, where a higher score indicates more satisfaction and better life quality [15]. We collected the data retrospectively for the purpose of the study from the patients' medical record at the first outpatient 
clinic before initiating treatment and at 3-month follow-up visit (approximately 1-month after the final MTP compression therapy session in the combined treatment group).

\section{Data analysis}

Continuous parameters are presented as means \pm standard deviation and categorical parameters are presented as proportions. Comparisons between the MTP group and the control group were performed using unpaired two-tailed t-test for continuous data and the Fisher's exact test for categorical data. Comparisons within each group between outcome measures before and after treatment were performed using paired two-tailed t-test. Data analysis was performed with the use of MedCalc Statistical Software version 19 (MedCalc Software bvba, Ostend, Belgium). With the alpha level set at 0.05, we determined that 34 patients per group would give $80 \%$ power of the test to identify a 1-point difference in 0-10 numerical pain score and a10-point difference in ODI between the groups.

\section{Results}

We identified 126 patients who followed our inclusion and exclusion criteria, 23 of these were removed from the study because of incomplete medical record with missing clinical or outcome measure data. One hundred and three patients were included in the study, 45 patients in the MTP compression therapy as an adjunct to exercise program group (combined treatment group) and 58 in the exercise program alone group. The mean age, gender distribution, body mass index and duration of symptoms were similar for both groups (Table 1). Baseline pain level and functional scores were also similar for both groups (Table 2). Patients' pain level decreased significantly following treatment at 3-month follow-up in both groups, however, pain reduction in the MTP group was significantly greater compared to the control group (5.6 points vs. 3.6 points respectively, $p<0.001$ ). Similarly, the ODI and SF-12 scores improved significantly following treatment in both study groups, but to a significantly greater extent in the MTP group. Specifically, the ODI score improved by $36 \%$ in the MTP group compared to $22 \%$ in the control group ( $p<0.001)$ and the SF-12 score improved by $41 \%$ compared to $29 \%$ respectively $(p<0.001)$. Comparisons of outcome measures between the groups and within each group before and after treatment are summarized in Table 2.

\section{Discussion}

Despite ample research in the field and numerous treatment options, chronic LBP of unknown origin remains a word wide concern and a major cause of disability. Current guidelines for the treatment of LBP endorse physical exercise programs and a range of other non-pharmacological complementary therapies including manual therapy, acupuncture, spinal manipulation and yoga [16]. Myofascial trigger points (MTP) compression therapy is a well-studied form of non-pharmacological complementary manual therapy, which aims to induce temporary local ischemia and over-stimulation of mechanoreceptors in 
order to restore tissue normal functional conditions and healing response [7-9]. The purpose of the current study was to evaluate the effect of MTP compression therapy as an adjunct to conservative physical therapy active exercise program in alleviating chronic non-specific low back pain and disability in adults.

Patients in our study demonstrated significant improvement in their pain and functional score, following participation in an active exercise program focusing on core muscle stretching and strengthening (improvement of 3.6 points in pain score, 22 points in ODI and 29 points in SF-12 score). Patients who were received combined treatment with MTP compression therapy in addition to active exercise program demonstrated superior improvement at 3-month follow-up (improvement of 5.6 points in pain score, 36 points in ODI and 41 points in SF-12 score). To note, the difference in pain scores between our study groups (Table 2) although statistically significant, remains below the minimal clinically important change for chronic LBP relief which is considered to be approximately 2.5 points on a $0-10$ numerical scale, and hardly reached the minimal clinically important change for ODI which is considered to be approximately 10 points [17].

Takamoto et al. [12] compared MTP compression therapy to other forms of manual therapy in 63 patients suffering from acute LBP and reported MTP to be the most effective form of manual therapy with pain relief equivalent to $5 / 10$ at 1 month following the end of treatment sessions. Schneider [10] evaluated a cohort of 30 patients with chronic LBP and compared the treatment outcome of MTP compression therapy with and without low-frequency shock wave therapy as an adjunct. Pain relief in his study following MTP compression therapy alone was equivalent to only $1 / 10$, while pain relief following combined therapy was approximately $3 / 10$. Comparing our results to those of others is difficult because of different set up between the studies. Nevertheless, we believe our favorable results in terms of pain relief, highlight the importance of adhering to current guidelines endorsing active exercise programs as a first-line treatment for LBP, and highlight the potential benefit of combining treatment strategies.

Our study has a number of limitations. Firstly, this was a retrospective non-randomized study with a limited cohort, a study design known to have inherent disadvantages. Secondly, outcomes were evaluated at a very short follow-up of 3 months from initiating treatment (approximately 1 month after the final MTP therapy session), which makes the duration of treatment efficacy unclear. Nevertheless, the prompt improvement in pain and functional scores of our patients after more than 12 months in average of disabling symptoms, suggests the treatment (especially in the MTP group) is effective regardless of its efficacy duration. Thirdly, since palpation of MTP may be less accurate in obese patients, we excluded patients with BMI greater than $30 \mathrm{~kg} / \mathrm{m} 2$, therefore, drawing conclusions from of our findings to the general population may be misleading. Finally, patients in the MTP group received more treatment sessions (and more personal nature of treatment during the manual MTP therapy sessions) compared to control patients, which may serve as a confounding factor affecting the outcomes.

In conclusion, our findings suggest that myofascial trigger points compression therapy as an adjunct to active exercise program for the treatment of chronic LBP, decreased pain and improved functional 
outcomes more than an exercise program alone, and emphasize the potential benefit of combining treatment strategies in patients with chronic LBP. Considering the limitations of the study our results should be interpreted with caution, and further higher-quality randomized clinical trials comparing different treatment strategies for LBP should be encouraged.

\section{List Of Abbreviations}

LBP: Low back pain; MTrPs: Myofascial trigger points; ODI: Oswestry Disability Index

\section{Declarations}

Ethics approval and consent to participate: The study was approved by our Institutional Ethics Committee, the requirement for informed consent was waived.

Consent for publication: Not applicable.

Availability of data and materials: The data used to support the findings of this study are available from the corresponding author upon request.

Competing interests: The authors declare that they have no competing interests.

Funding: None of the authors received any funding or grants in support of their research for preparation of this work.

Authors' contributions: RM and OU designed the study, analysed and interpreted the data and were the major contributors in writing the manuscript. GP, GL and GG collected, analysed and interpreted the data. EB contributed to the data acquisition and analysis and substantively revised the manuscript. All authors read and approved the final version of the manuscript.

Acknowledgement: Not applicable.

Authors' Information: Department of Orthopedic Surgery, Hillel Yaffe Medical Center, Hadera, Israel.

\section{References}

1. Uhl RL, Roberts TT, Papaliodis DN, Mulligan MT, Dubin AH. Management of chronic musculoskeletal pain. J Am Acad Orthop Surg. 2014;22(2):101-10. doi: 10.5435/JAAOS-22-02-101.

2. Hartvigsen J, Hancock MJ, Kongsted A, Louw Q, Ferreira ML, Genevay S, Hoy D, Karppinen J, Pransky G, Sieper J, Smeets RJ Underwood M; Lancet Low Back Pain Series Working Group. What low back pain is and why we need to pay attention. Lancet. 2018;391(10137):2356-2367. doi: 10.1016/S01406736(18)30480-X.

3. Shah JP, Thaker N, Heimur J, Aredo JV, Sikdar S, Gerber L. Myofascial Trigger Points Then and Now: A Historical and Scientific Perspective. PM R. 2015;7(7):746-761. doi: 10.1016/j.pmrj.2015.01.024. 
4. Ramsook RR, Malanga GA. Myofascial low back pain. Curr Pain Headache Rep. 2012;16(5):423-32. doi: 10.1007/s11916-012-0290-y.

5. Weller JL, Comeau D, Otis JAD. Myofascial Pain. Semin Neurol. 2018; 38(6):640-643. doi: 10.1055/s0038-1673674.

6. Shipton EA. Physical Therapy Approaches in the Treatment of Low Back Pain. Pain Ther. 2018;7(2):127-137. doi: 10.1007/s40122-018-0105-x.

7. Kisilewicz A, Janusiak M, Szafraniec R, Smoter M, Ciszek B, Madeleine P, Fernandez-de-Las-Peñas C, Kawczynski A. Changes in muscle stiffness of the trapezius muscle after application of ischemic compression into myofascial trigger points in professional basketball players. J Hum Kinet. 2018;64:35-45. doi: 10.2478/hukin-2018-0043.

8. Simons DG. New views of myofascial trigger points: etiology and diagnosis. Arch Phys Med Rehabil. 2008;89(1):157-9. doi: 10.1016/j.apmr.2007.11.016.

9. Shah JP, Danoff JV, Desai MJ, Parikh S, Nakamura LY, Phillips TM, Gerber LH. Biochemicals associated with pain and inflammation are elevated in sites near to and remote from active myofascial trigger points. Arch Phys Med Rehabil. 2008;89(1):16-23. doi: 10.1016/j.apmr.2007.10.018.

10. Schneider R. Effectiveness of myofascial trigger point therapy in chronic back pain patients is considerably increased when combined with a new, integrated, low-frequency shock wave vibrotherapy (Cellconnect Impulse): A two-armed, measurement repeated, randomized, controlled pragmatic trial. J Back Musculoskelet Rehabil. 2018;31(1):57-64. doi: 10.3233/BMR-169662.

11. Hains G, Boucher PB, Lamy AM. Ischemic compression and joint mobilisation for the treatment of nonspecific myofascial foot pain: findings from two quasi-experimental before-and-after studies. $J$ Can Chiropr Assoc. 2015;59(1):72-83.

12. Takamoto K, Bito I, Urakawa S, Sakai S, Kigawa M, Ono T, Nishijo H. Effects of compression at myofascial trigger points in patients with acute low back pain: A randomized controlled trial. Eur $\mathrm{J}$ Pain. 2015;19(8):1186-96. doi: 10.1002/ejp.694.

13. Gerwin RD, Shannon S, Hong CZ, Hubbard D, Gevirtz R. Interrater reliability in myofascial trigger point examination. Pain. 1997;69(1-2):65-73

14. Dorit Gamus, Saralee Glasser, Elisheva Langner, Aliza Beth-Hakimian, Israel Caspi, Narin Carmel, Itzhak Siev-Ner, Hagai Amir, A Ziv, M Papa, Liat Lerner-Geva. Psychometric properties of the Hebrew version of the Oswestry Disability Index. J Back Musculoskelet Rehabil. 2016 Jun 17. doi: 10.3233/BMR-160726.

15. Marianne Amir, Noah Lewin-Epstein, Gideon Becker, Dan Buskila. Psychometric properties of the SF12 (Hebrew version) in a primary care population in Israel. Med Care. 2002;40(10):918-28. doi: 10.1097/00005650-200210000-00009.

16. Foster NE, Anema JR, Cherkin D, Chou R, Cohen SP, Gross DP, Ferreira PH, Fritz JM, Koes BW, Peul W, Turner JA, Maher CG; Lancet Low Back Pain Series Working Group. Prevention and treatment of low 
back pain: evidence, challenges, and promising directions. Lancet. 2018;391(10137):2368-2383. doi: 10.1016/S0140-6736(18)30489-6.

17. Ostelo RW, de Vet HC. Clinically important outcomes in low back pain. Best Pract Res Clin Rheumatol. 2005;19(4):593-607. doi: 10.1016/j.berh.2005.03.003.

\section{Tables}

\begin{tabular}{|c|c|c|c|c|}
\hline & $\begin{array}{c}\text { Active exercise program } \\
\text { with MTP therapy } \\
(\mathrm{N}=45)\end{array}$ & $\begin{array}{l}\text { Active exercise } \\
\text { program alone } \\
(\mathrm{N}=58)\end{array}$ & $\begin{array}{c}\text { [Difference] } \\
(95 \% \mathrm{CI})\end{array}$ & $\begin{array}{c}\mathrm{p} \\
\text { value }\end{array}$ \\
\hline Age, years & $55 \pm 14$ & $52 \pm 17$ & $3(-3,9)$ & 0.34 \\
\hline $\begin{array}{l}\text { Gender, n (\%) } \\
\text { 1. Female } \\
\text { 2. Male }\end{array}$ & $\begin{array}{l}26(58 \%) \\
19(42 \%)\end{array}$ & $\begin{array}{l}32(55 \%) \\
26(45 \%)\end{array}$ & $\begin{array}{c}2.6(-0.1 \\
0.2)\end{array}$ & 0.84 \\
\hline BMI, $\mathrm{kg} / \mathrm{m}^{2}$ & $25.3 \pm 3.2$ & $24.6 \pm 4.3$ & $\begin{array}{c}0.7(-0.8 \\
2.2)\end{array}$ & 0.36 \\
\hline $\begin{array}{l}\text { LBP duration, } \\
\text { months }\end{array}$ & $18 \pm 24$ & $16 \pm 17$ & $2(-6,10)$ & 0.62 \\
\hline \multicolumn{5}{|c|}{$\begin{array}{l}\text { Values are presented as mean } \pm \text { standard deviation. Comparisons between the groups } \\
\text { were performed using unpaired two-tailed t-test, apart from age parameters which were } \\
\text { compared using Fisher's exact test. SD-Standard deviation; BMI-Body mass index; LBP- } \\
\text { Low back pain. }\end{array}$} \\
\hline
\end{tabular}




\begin{tabular}{|c|c|c|c|c|}
\hline & $\begin{array}{c}\text { Active exercise program } \\
\text { with MTP therapy }(\mathrm{N}=45)\end{array}$ & $\begin{array}{c}\text { Active exercise } \\
\text { program alone } \\
(\mathrm{N}=58)\end{array}$ & $\begin{array}{c}\text { [Difference] } \\
(95 \% \mathrm{CI})\end{array}$ & $\begin{array}{c}\mathrm{p} \\
\text { value* }\end{array}$ \\
\hline $\begin{array}{l}\text { Pain level, 0- } \\
\text { 10 scale } \\
\text { 1. Baseline } \\
\text { 2. 3-month } \\
\text { follow-up } \\
\text { 3. p value } \\
\text { 4. [Difference] }\end{array}$ & $\begin{array}{c}7.8 \pm 1.2 \\
2.2 \pm 1.8 \\
<0.001 \\
5.6 \pm 2.1\end{array}$ & $\begin{array}{c}7.4 \pm 2.1 \\
3.8 \pm 2.3 \\
<0.001 \\
3.6 \pm 2.5\end{array}$ & $\begin{array}{c}0.4(-0.3 \\
1.1) \\
1.6(0.8 \\
2.4) \\
2.0(1.1 \\
2.9)\end{array}$ & $\begin{array}{l}0.25 \\
<0.01 \\
<0.01\end{array}$ \\
\hline $\begin{array}{l}\text { ODI, } 0-100 \% \\
\text { scale } \\
\text { 1. Baseline } \\
\text { 2. 3-month } \\
\text { follow-up } \\
\text { 3. p value } \\
\text { 4. [Difference] }\end{array}$ & $\begin{array}{l}49 \pm 16 \\
13 \pm 15 \\
<0.001 \\
36 \pm 18\end{array}$ & $\begin{array}{l}45 \pm 20 \\
23 \pm 17 \\
<0.001 \\
22 \pm 21\end{array}$ & $\begin{array}{c}4(-3.2,11) \\
10(3.6 \\
16) \\
14(6.2,22)\end{array}$ & $\begin{array}{l}0.28 \\
<0.01 \\
<0.01\end{array}$ \\
\hline $\begin{array}{l}\text { SF-12, 0- } \\
\text { 100\% scale } \\
\text { 1. Baseline } \\
\text { 2. 3-month } \\
\text { follow-up } \\
\text { 3. p value } \\
\text { 4. [Difference] }\end{array}$ & $\begin{array}{l}36 \pm 22 \\
77 \pm 21 \\
<0.001 \\
41 \pm 20\end{array}$ & $\begin{array}{l}38 \pm 26 \\
67 \pm 24 \\
<0.001 \\
29 \pm 23\end{array}$ & $\begin{array}{l}2(-7.5,11) \\
10(1.0,19) \\
12(3.4,20)\end{array}$ & $\begin{array}{l}0.68 \\
0.03 \\
<0.01\end{array}$ \\
\hline \multicolumn{5}{|c|}{$\begin{array}{l}\text { Values are presented as mean } \pm \text { standard deviation. Differences are presented in absolute } \\
\text { value. } \\
* \text { Comparisons between the groups were performed using unpaired two-tailed t-test. } \\
\text { tComparisons within each group were performed using paired two-tailed t-test. } \\
\text { MTP-Myofascial trigger points; ODI-Oswesrty disability index. }\end{array}$} \\
\hline
\end{tabular}

